TITLE:

\title{
Evaluation of Flowability of Composite Particles and Powder Mixtures by a Vibrating Capillary Method
}

\section{$\operatorname{AUTHOR}(\mathrm{S}):$}

Jiang, Yanbin; Matsusaka, Shuji; Masuda, Hiroaki; Yokoyama, Toyokazu

\section{CITATION:}

Jiang, Yanbin ...[et al]. Evaluation of Flowability of Composite Particles and Powder Mixtures by a Vibrating Capillary Method. Journal of Chemical Engineering Japan 2006, 39(1): 14-21

\section{ISSUE DATE:}

2006

URL:

http://hdl.handle.net/2433/229146

\section{RIGHT:}

Publisher permitted to deposit the accepted manuscript on this repository. 発行元の許可 を得て登録しています.; This is not the published version. Please cite only the published version.; この論文は出版社版でありません。引用の際には出版社版をご確認ご利用くだ さい。 


\title{
Research Paper
}

Evaluation of Flowability of Composite Particles and Powder Mixtures by a Vibrating Capillary Method

Yanbin JIANG ${ }^{1,2}$, Shuji MATSUSAKA ${ }^{1 *}$, Hiroaki MASUDA ${ }^{1}$ and Toyokazu YOKOYAMA $^{3}$

1. Department of Chemical Engineering, Kyoto University, Nishikyo-ku, Kyoto-shi, Kyoto 606-8501, Japan

2. Research Institute of Chemical Engineering, South China University of Technology, Guangzhou 510640, China

3. Hosokawa Micron Corporation, 9, 1-chome, Shodai Tajika., Hirakata-shi, Osaka 573-1132, Japan

Keywords: Flowability, Composite Particle, Powder Mixture, Vibrating Capillary Tube, Mechanofusion

\begin{abstract}
Flowability of micrometer-sized particles treated with nanometer-sized particles has been studied by a vibrating capillary method. Two different types of treatments, i.e. dry particle coating based on the mechanofusion and simple mixing through shaking manually, were adopted to prepare composite particles and powder mixtures, respectively. The micrometer-sized core particle was polymethylmethacrylate (PMMA), and the coating nano-particles were $\mathrm{TiO}_{2}, \mathrm{Al}_{2} \mathrm{O}_{3}$, or $\mathrm{SiO}_{2}$. Surface morphology of the treated particles was
\end{abstract}

\footnotetext{
* To whom correspondence should be addressed. E-mail: matsu@cheme.kyoto-u.ac.jp
} 
analyzed by digital processing of SEM photographs, and flow behavior of powders in the vibrating capillary tube was studied with particular attention to the effects of the kind of nano-particles, its concentration, and the treatment method. Two factors were introduced to evaluate the flowability; one is the critical amplitude of vibration making the powder flow, and the other is the mass flow rate as a function of the vibration amplitude. The experimental results show that the mechanofusion treatment gave a remarkable improvement in the powder flowability evaluated by the two factors mentioned above. The general tendency of the improvement can be explained by the projected-area ratio defined as the ratio of the total projected-area of nano-particles adhering to core-particle surface and the projected-area of the core-particle itself.

\section{Introduction}

Flowability of powders is of great industrial interest so as to improve powder handling processes. It is practically well known that a small amount of additives could improve the flowability of powders. Such an additive is called glidant and often incorporated into various cohesive powders (Peleg and Mannheim, 1973; York, 1975; Jonat et al., 2004; Meyer and Zimmermann, 2004; Zimmermann et al., 2004). However, the mechanism of the function of glidant is not yet clear. The following factors have been suggested for the flowability improvement: (a) change in the surface properties, (b) alteration in particle arrangement, (c) reduction of interaction forces between particles, (d) enhancement in electrostatic discharge (Peleg and Mannheim, 1973; York, 1975; Yokoyama, 1997). Also, it has been pointed out that composite particles formed by a mechanical treatment show higher flowability (Yokoyama, 1997; Pfeffer, et al., 2001).

For evaluating the flowability of powders, several tests have been proposed, e.g. Carr's flowability index obtained with the Powder Characteristics Tester (for example; Masuda, et 
al., 1975; Yokoyama, 1997), flow factor measured with the Jenike Shear Tester (Yokoyama, 1997; Schwedes, 2003) and flowability determined with the Hall-flowmeter subjected to vibration (Staffa, et al., 1977). The Hall-flowmeter might be useful since the powder is actually flowing during the test; however, the evaluation factor is only the time required for a $50 \mathrm{~g}$ sample to flow through a standardized funnel. From the viewpoint of highly-sensitive measurement, well-defined evaluation factors and also a small testing device to detect a slight difference of flowability of fine powders are required.

A method using a vibrating capillary tube has been developed to control the mass flow rate of fine powders (Matsusaka et al., 1995, 1996; Yang and Li, 2003; Yang and Evans, 2003, 2005). Using the vibrating capillary tube technique, the flowability of fine powders will be characterized in actual powder flow through obtaining the critical amplitude of vibration making the powder flow and the mass flow rate as a function of the amplitude of vibration.

In the present work, micrometer-sized polymer particles are treated with nanometer-sized inorganic particles under various operating conditions and the surface morphology of the particles is analyzed. The flowability of the powders is evaluated by the vibrating capillary method, and the effect of the surface morphology on the flowability is also discussed.

\section{Experimental Procedures}

\subsection{Preparation of sample powders}

To prepare composite particles and powder mixtures, micrometer-sized polymethylmethacrylate (PMMA) particles and nanometer-sized inorganic particles, i.e. $\mathrm{TiO}_{2}$, $\mathrm{Al}_{2} \mathrm{O}_{3}$, or $\mathrm{SiO}_{2}$ particles were used as raw materials. The mass median diameter and the specific surface area of these materials are listed in Table 1, and the SEM photographs of the core particles (PMMA) and the coating particles $\left(\mathrm{TiO}_{2}\right)$ are shown in Figure 1. The PMMA particles are spherical and almost mono-disperse ( $9.4 \mu \mathrm{m}$ in mass median diameter), however, 
its surface is not smooth and some concavities can be seen. The coating particles are as small as $14-16 \mathrm{~nm}$ in mass median diameter, and they have high cohesiveness.

In this work, two different types of treatments, i.e. dry particle coating and simple mixing were adopted. The Mechanofusion ${ }^{\circledR}$ system (AM-15F, Hosokawa Micron Ltd.) was used for the dry particle coating. This system consists of a main rotating chamber and inner pieces (Yokoyama et al., 1987). The main chamber rotates with high speed, and inner pieces are fixed on the inner wall of the chamber with a certain clearance. The raw materials, i.e., PMMA particles and one of the nano-particle samples were put in the chamber. The system was operated at a rotational speed of $2000 \mathrm{rpm}$ for $15 \mathrm{~min}$. Particles are pressed onto the inner wall by the centrifugal force, and then experience various forces in the clearance, e.g. compressing, shearing, and rolling. Experiments have been conducted under the condition that the concentration of added nano-particles is not more than $10 \mathrm{wt} \%$. Even for the $0 \mathrm{wt} \%$ test, the PMMA particles were treated by the same procedure to standardize the experimental condition. For the simple mixing treatment, two raw materials were put into a small vessel and shaken manually for $1 \mathrm{~min}$.

\subsection{Physical characterization and analysis of surface morphology of particles after}

\section{treatment}

Particle size distribution was measured with a particle size analyzer (X-100, Microtrac, Inc.), and the surface of particles was observed through a scanning electron microscope (S-3500N, Hitachi Ltd.) where the magnification of observation was 1500 times or 5000 times. The surface morphology of the particles was analyzed using an image processing system (Image-Pro Plus 4.0, Media Cybernetics, Inc.), and the projected-area ratio $S_{\mathrm{r}}$ was obtained by digital processing of SEM photographs. Here, the projected-area ratio $S_{\mathrm{r}}$ is defined as the ratio of the total projected-area of nano-particles adhering to core-particle surface and the projected-area of the core-particle itself. The SEM photographs of the 
particles treated under different conditions are shown in Figure 2 with the corresponding values of $S_{\mathrm{r}}$ for reference.

\subsection{Measurement of flowability}

The mechanism of the powder flow in the vibrating capillary tube has been discussed elsewhere (Matsusaka et al.,1996). The gravitational force is the main factor for the discharge of powder from the capillary tube, while the adhesive force and the friction force between particles and the capillary wall are the hindrances. If the capillary tube is horizontally vibrated, the forces will be reduced because a clearance is made between the powder and the inner wall. As a result, the powder can move down through the tube. Also, the vibration can cause the consolidation of powders (Matsusaka et al., 1996) and the reduction in the effective passage through the tube (Yang and Evans, 2003), and thus makes it difficult to discharge the powder. Therefore, there are optimum conditions of vibration for flowing and discharging powders.

Figure 3 shows a schematic diagram of the experimental apparatus. A glass tube, 100 $\mathrm{mm}$ long and $6 \mathrm{~mm}$ inner diameter, with a capillary tube, $50 \mathrm{~mm}$ long and $1.2 \mathrm{~mm}$ inner diameter, was held vertically. The hopper on the top was kept full with a sample powder during the measurement, and the test was carried out immediately after filling the powder. Sinusoidal vibration was added to the capillary tube in the horizontal direction by a piezoelectric vibrator where the mode of the vibration can be controlled by a computer. Frequency and amplitude of the sinusoidal vibration were measured at the end of the capillary tube by a laser vibrometer (LV-1300, Ono-sokki Co., Ltd.) and recorded into the computer via an A/D converter (NR-350, Keyence Corp.). The mass flow rate of the powder was measured with a resolution of $0.1 \mathrm{mg}$ by weighing the discharged powder using an electric balance where the measuring time is three minutes, and measurements were repeated three times under the same conditions to confirm the repeatability. The frequency $f$ was fixed at 
$400 \mathrm{~Hz}$, which corresponded to a resonance point of this system. The amplitude of vibration was varied in the range of 0 to $80 \mu \mathrm{m}$. All the experiments were conducted under room conditions (temperature: $17-20{ }^{\circ} \mathrm{C}$, relative humidity: $35-45 \%$ ). Electrostatic charge of particles was also measured by a Faraday cage and found to be less than $1.5 \times 10^{-5} \mathrm{C} / \mathrm{kg}$. Therefore, the van der Waals force exerted on the particles is thought to be dominant in this experiment.

\section{Results and Discussion}

\subsection{Physical characterization and analysis of surface morphology of sample powders}

Table 2 shows the results obtained by the particle size analyzer. The diameter of particles after mechanofusion treatment increased with the concentration of nano-particles. The mass median diameter of the core particles (PMMA) was $9.4 \mu \mathrm{m}$ (see Table 1), and that for the concentration of $10 \mathrm{wt} \% \mathrm{TiO}_{2}$ was $10.0 \mu \mathrm{m}$. Also, the change in the diameter was affected by the kind of nano-particles in the order of $\mathrm{TiO}_{2}>\mathrm{Al}_{2} \mathrm{O}_{3}>\mathrm{SiO}_{2}$ (at $5 \mathrm{wt} \%$ ). On the other hand, the diameter under simple mixing treatment did not increase with the concentration of nano-particles. For some cases, the measured values were lower than those of the core particles. This is because the PMMA particles were scarcely coated and smaller agglomerates $(<3 \mu \mathrm{m})$ consisting of nano-particles remained in the powder mixtures.

Figure 4 shows the SEM photographs of the composite particles formed by the mechanofusion treatment. When the concentration of added nano-particles was relatively low, some concavities on the surface of core particles were embedded by nano-particles giving a smaller surface roughness. However, as the amount of nano-particles adhering to PMMA core particles increased with the concentration of nano-particles, the roughness of the composite particles also increased. At higher concentrations, a large amount of nano-particles covered the surface of the core particles. The amount and the form of 
nano-particles on the PMMA particle surface were influenced by the kind of nano-particles. The surface treatment with $\mathrm{SiO}_{2}$ nano particles was less effective to cover the core-particle surface than that with other nano-particles, and non-mechanofused nano-particles remained as small agglomerates.

Figure 5 shows the SEM photographs of the PMMA particles treated by the simple mixing method. A small amount of nano-particles were seen on the surface of PMMA particles slightly increasing with the concentration of nano-particles. However, a large amount of nano-particles remained in the powder mixture as small agglomerates (see irregular shaped agglomerate in the photograph; $5 \mathrm{wt} \% \mathrm{SiO}_{2}$ ). Such agglomerates might have some adverse effect on the flowability of powders.

To quantitatively evaluate the surface morphology of particles, the projected-area ratio $S_{\mathrm{r}}$ was obtained by digital processing of SEM photographs. The results are shown in Figure 6. The projected-area ratio generally increases with the concentration of nano-particles. For the particles obtained by the mechanofusion, the values of $S_{\mathrm{r}}$ are rather high, and the effect of the kind of nano-particles on the projected-area ratio is in the order of $\mathrm{TiO}_{2}>\mathrm{Al}_{2} \mathrm{O}_{3}>\mathrm{SiO}_{2}$, while the values for particles obtained by the simple mixing treatment are rather low.

\subsection{Observation of the powder flow in a vibrating capillary tube}

When the amplitude exceeded a certain value, the powder began to flow in the capillary tube. However, when the amplitude was not sufficiently high, powder flow was intermittent. In this situation, formation and breakage of arches were observed repeatedly. On the other hand, when the amplitude is sufficiently large, the particles treated by the mechanofusion system with a few wt $\%$ of nano-particles or more was able to flow like a fluid. The simple mixing particles showed unstable flow or did not flow even at high amplitude.

\subsection{Results for critical amplitude}


Figure 7 shows the relationship between the critical amplitude of vibration making a flow and the concentration of nano-particles. For the treatment with $\mathrm{TiO}_{2}$ or $\mathrm{Al}_{2} \mathrm{O}_{3}$ nano-particles, the critical amplitude decreased rapidly with the increase in the concentration and reached a lower limit. On the other hand, for the mechanofusion treatment with $\mathrm{SiO}_{2}$ nano-particles, the critical amplitude increased at lower concentrations and then decreased. As for simple mixing with $\mathrm{SiO}_{2}$ nano-particles, the powder did not flow at any amplitude of vibration, this adverse effect might be caused by the small agglomerates of $\mathrm{SiO}_{2}$ nano-particles remained, as mentioned in section 2.1 .

\subsection{Results for mass flow rate}

Figure 8 shows the experimental results for the mass flow rate of the particles treated by the mechanofusion system. The mass flow rate increases with the amplitude of vibration exceeding the critical value. However, there is an upper limit of the flow rate according to the conditions. This can be explained as follows: when the vibration overcomes the interaction forces between particles and the wall, the flowability will be improved. Nevertheless, if the amplitude of the horizontal vibration is too large, the powder flow will be prevented because of the consolidation (Matsusaka et al., 1996) and the reduction of the effective passage in the tube (Yang and Evans, 2003). It was also found that the mass flow rate tends to increase with the concentration of added nano-particles although there are a few exceptions at lower concentrations of $\mathrm{Al}_{2} \mathrm{O}_{3}$ and $\mathrm{SiO}_{2}$. The reason for this adverse effect might be deduced that the nano-particles is so small that they act mainly as the filler for the concavity of PMMA particles, and the initial surface roughness is decreased as mentioned in section 2.1.

Figure 9 shows the experimental results for the mass flow rate of particles obtained by the simple mixing treatment. The features of the mass flow rate curve for $\mathrm{PMMA}^{-\mathrm{TiO}_{2}}$ are similar to those for the mechanofusion-treated particles, while the features for $\mathrm{PMMA}-\mathrm{Al}_{2} \mathrm{O}_{3}$ 
are somewhat complicated and the effect of the nano-particle concentration on the mass flow rate is not very clear. PMMA- $\mathrm{SiO}_{2}$ particles obtained by the simple mixing did not flow under any conditions.

As the mass flow rate depends on the amplitude of vibration, it is difficult to understand the effect of the sample preparation such as the kind of nano-particles, its concentration and/or the treatment method; thus, we focused on the maximum mass flow rate. Figure 10 shows the experimental results. In general, the maximum mass flow rate of particles treated by the mechanofusion system is higher than that of the particles obtained by simple mixing, and increases with the concentration of nano-particles although the increasing rate gradually decreases. This indicates that there are proper concentrations of added nano-particles for effective improvement of flowability. Effectiveness of the improvement depends on the kind of nano-particles in the order of $\mathrm{TiO}_{2}>\mathrm{Al}_{2} \mathrm{O}_{3}>\mathrm{SiO}_{2}$. This is the same order as the projected-area ratio and thus should be considered connecting with the surface morphology of particles.

\subsection{Effect of surface morphology on flowability}

Figure 11 shows the relationship between the critical amplitude of vibration making a flow and the projected-area ratio $S_{\mathrm{r}}$. The critical amplitude tends to decrease with the increase in the projected-area ratio. In particular, the decrease in the critical amplitude is remarkable at lower values of $S_{\mathrm{r}}$ less than 0.1. The critical amplitude for the simple mixing particles is lower than that for the mechanofusion-treated particles as far as the projected-area ratio is kept constant. This does not imply that the simple mixing is more effective for the improvement of the flowability because the amount of the nano-particles used for the simple mixing is much larger than that adhering to the core-particles.

Figure 12 shows the relationship between the maximum mass flow rate and the projected-area ratio. The data scatter because $\mathrm{SiO}_{2}$ simple mixing particles do not flow as 
mentioned above, but the maximum mass flow rate increases with the projected-area ratio as a rough tendency.

As discussed above, the flowability of powders varies according to the surface morphology of particles and depends on the secondary factors, such as the kind of nano-particles, concentration of added nano-particles and/or the surface treatment method.

\section{Conclusions}

The surface of the micrometer-sized PMMA particles was mechanically treated with nanometer-sized $\mathrm{TiO}_{2}, \mathrm{Al}_{2} \mathrm{O}_{3}$ or $\mathrm{SiO}_{2}$ particles. Two different types of treatments, i.e. dry particle coating by mechanofusion and simple mixing by shaking manually, were adopted, and the surface morphology of the particles was analyzed. Also, the flowability of the powders was evaluated by the method based on the actual powder flow in a vibrating capillary tube. The results obtained are summarized as follows.

The projected-area ratio of the particles treated by the mechanofusion system increased with the concentration of added nano-particles, and the effect of the kind of nano-particles on the projected-area ratio was in the order of $\mathrm{TiO}_{2}>\mathrm{Al}_{2} \mathrm{O}_{3}>\mathrm{SiO}_{2}$. On the other hand, the simple mixing treatment was not effective for the coating, and the attainable projected-area ratio was rather low.

The flowability of powders was evaluated by two factors, i.e. the critical amplitude of vibration making the powder flow and the mass flow rate. These two factors vary according to the surface morphology of particles, which depends on the conditions of the surface treatment. The mechanofusion treatment was found to provide a remarkable improvement in the flowability compared to simple mixing. The flowability was improved with the increase in the concentration of added nano-particles, and the effectiveness of the kind of nano-particles on the improvement of flowability was in the order of $\mathrm{TiO}_{2}>\mathrm{Al}_{2} \mathrm{O}_{3}>\mathrm{SiO}_{2}$. 


\section{Acknowledgement}

The authors gratefully acknowledge the support for this research by Kyoto Prefecture Collaboration of Regional Entities for the Advancement of Technological Excellence, JST.

\section{Nomenclature}

$a=$ amplitude of vibration $[\mu \mathrm{m}]$

$a_{\mathrm{c}} \quad=$ critical amplitude that makes a flow $[\mu \mathrm{m}]$

$c=$ concentration of nano-particles $[\mathrm{wt} \%]$

$S_{\mathrm{r}} \quad=$ projected area ratio of nano-particles [ - ]

$w \quad=$ mass flow rate of powder $[\mathrm{mg} / \mathrm{s}]$

$w_{\max }=$ maximum mass flow rate of powder $[\mathrm{mg} / \mathrm{s}]$

\section{Literature Cited}

Jonat, S., S. Hasenzahl, M. Drechsler, P. Albers, K.G. Wagner and P.C. Schmidt; "Investigation of Compacted Hydrophilic and Hydrophobic Colloidal Silicon Dioxides as Glidants for Pharmaceutical Excipients," Powder Technol., 141, 31-43 (2004)

Masuda, H., H. Yoshida and K. Iinoya; "Statistical Analysis of the Carr's Flowability Index," Journal of the Research Association of Powder Technology, Japan, 12, 209-216 (1975)

Matsusaka, S., M. Urakawa and H. Masuda; "Micro-feeding of Fine Powders Using a Capillary Tube with Ultrasonic Vibration," Adv. Powder Technol., 6, 283-293 (1995)

Matsusaka, S., K. Yamamoto and H. Masuda; "Micro-feeding of a Fine Powder Using a Vibrating Capillary Tube,” Adv. Powder Technol., 7, 141-151 (1996)

Meyer, K. and I. Zimmermann; "Effect of Glidants in Binary Powder Mixtures," Powder Technol., 139, 40-54 (2004) 
Peleg, M. and C. H. Mannheim; "Effect of Conditioners on the Flow Properties of Powdered Sucrose," Powder Technol., 7, 45-50 (1973)

Pfeffer, R., R. N. Dave, D. Wei and M. Ramlakhan; "Synthesis of Engineered Particulates with Tailored Properties using Dry Particle Coating," Powder Technol., 117, 40-67 (2001)

Schwedes, J., "Review on Testers for Measuring Flow Properties of Bulk Solids," Granul. Matter, 5, 1-43 (2003)

Staffa, K.H., J. Jahn and N. Claussen; "Flowability of Powders under the Influence of Vibrations," Powder Metallurgy International, 9, 20-23 (1977)

Yang, S. and J. R. G. Evans; “Computer Control of Powder Flow for Solid Freeforming by Acoustic Modulation," Powder Technol., 133, 251-254 (2003)

Yang, S. and J. R. G. Evans; “Acoustic Initiation of Powder Flow in Capillaries,” Chem. Eng. Sci., 60, 413-421 (2005)

Yang, Y., and X. Li; "Experimental and Analytical Study of Ultrasonic Micro Powder Feeding," Journal of Physics D: Applied Physics, 36, 1349-1354 (2003)

Yokoyama, T., K. Urayama, M. Naito, M. Kato and T. Yokoyama; "The Angmill Mechanofusion System and Its Applications," KONA, 5, 59-68 (1987)

Yokoyama, T.; "Fluidity of Powder", Powder Technology Handbook, 2nd ed., in K. Gotoh, H. Masuda, K. Higashitani eds., pp. 413-425, Marcel Dekker, New York, U.S.A. (1997)

York, P.; "The Use of Glidants to Improve the Flowability of Fine Lactose Powder," Powder Technol., 11, 197-198 (1975)

Zimmermann, I., M. Eber and K. Meyer; "Nanomaterials as Flow Regulators in Dry Powders,” Z. Phys. Chem., 218, 51-102 (2004) 
Table 1 Properties of core and coating materials

\begin{tabular}{lccc}
\hline Category & Material & Mass median diameter $[\mu \mathrm{m}]$ & Specific surface area $\left[\mathrm{m}^{2} / \mathrm{g}\right]$ \\
\hline Core & PMMA & $9.4^{* 1}$ & $0.61^{* 3}$ \\
Additives & $\mathrm{TiO}_{2}$ & $0.015^{* 2}$ & $81^{* 3}$ \\
& $\mathrm{Al}_{2} \mathrm{O}_{3}$ & $0.014^{* 2}$ & $104^{* 3}$ \\
& $\mathrm{SiO}_{2}$ & $0.016^{* 2}$ & $74^{* 3}$ \\
\hline
\end{tabular}

*1 Laser diffraction analysis using unified scatter technique, *2 nominal value, *3 BET adsorption method

Table 2 Mass median diameter of particles after treatment

\begin{tabular}{cccc}
\hline Nano-particles & \multicolumn{2}{c}{ Mass median diameter ${ }^{* 1}, \mathrm{Dp}_{50}[\mu \mathrm{m}]$} \\
(concentration) & Mechanofusion & Simple mixing \\
\hline $\mathrm{TiO}_{2}$ & $(1 \mathrm{wt} \%)$ & 9.6 & 9.4 \\
$\mathrm{TiO}_{2}$ & $(5 \mathrm{wt} \%)$ & 9.8 & 9.4 \\
$\mathrm{TiO}_{2}$ & $(10 \mathrm{wt} \%)$ & 10.0 & 9.2 \\
$\mathrm{Al}_{2} \mathrm{O}_{3}$ & $(5 \mathrm{wt} \%)$ & 9.6 & 9.3 \\
$\mathrm{SiO}_{2}$ & $(5 \mathrm{wt} \%)$ & 9.5 & 9.4 \\
\hline
\end{tabular}

*1 Laser diffraction analysis using unified scatter technique 


\section{図表タイトル}

Table 1 Properties of core and coating materials

Table 2 Mass median diameter of particles after treatment

Fig. 1 SEM photographs of core and coating particles

Fig. 2 SEM photographs of particles after treatment with nano-particles under different conditions

Fig. 3 Experimental apparatus for measuring flowability of powders

Fig. 4 SEM photographs of particles treated by mechanofusion method

Fig. 5 SEM photographs of particles treated by simple mixing method

Fig. 6 Characterization of particle surface morphology

Fig. 7 Relationship between critical amplitude of vibration and concentration of nano-particles $(f=400 \mathrm{~Hz})$

Fig. 8 Mass flow rates of particles after mechanofusion treatment $(f=400 \mathrm{~Hz})$

Fig. 9 Mass flow rates of particles after simple mixing $(f=400 \mathrm{~Hz})$

Fig. 10 Relationship between maximum mass flow rate and concentration of nano-particles $(f=400 \mathrm{~Hz})$

Fig. 11 Relationship between critical amplitude of vibration and projected area ratio of nano-particles $(f=400 \mathrm{~Hz})$

Fig. 12 Relationship between maximum mass flow rate and projected area ratio of nano-particles $(f=400 \mathrm{~Hz})$ 


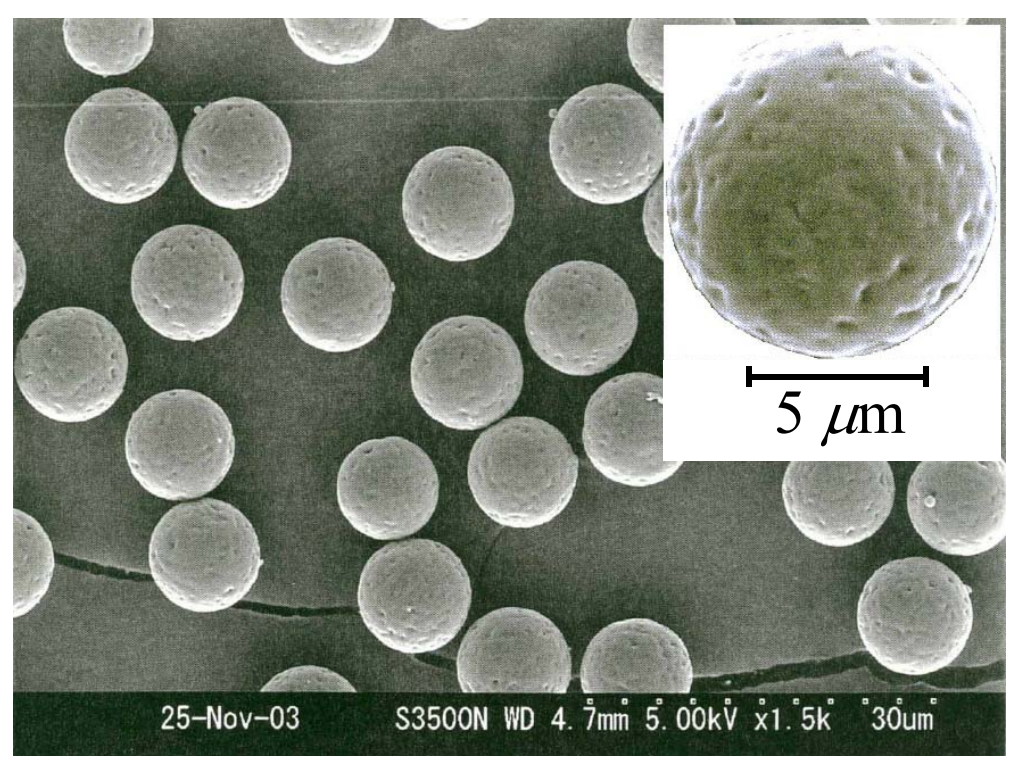

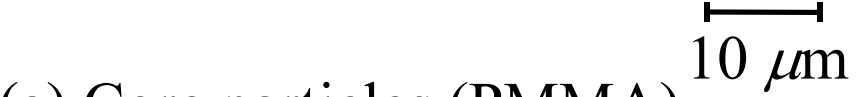

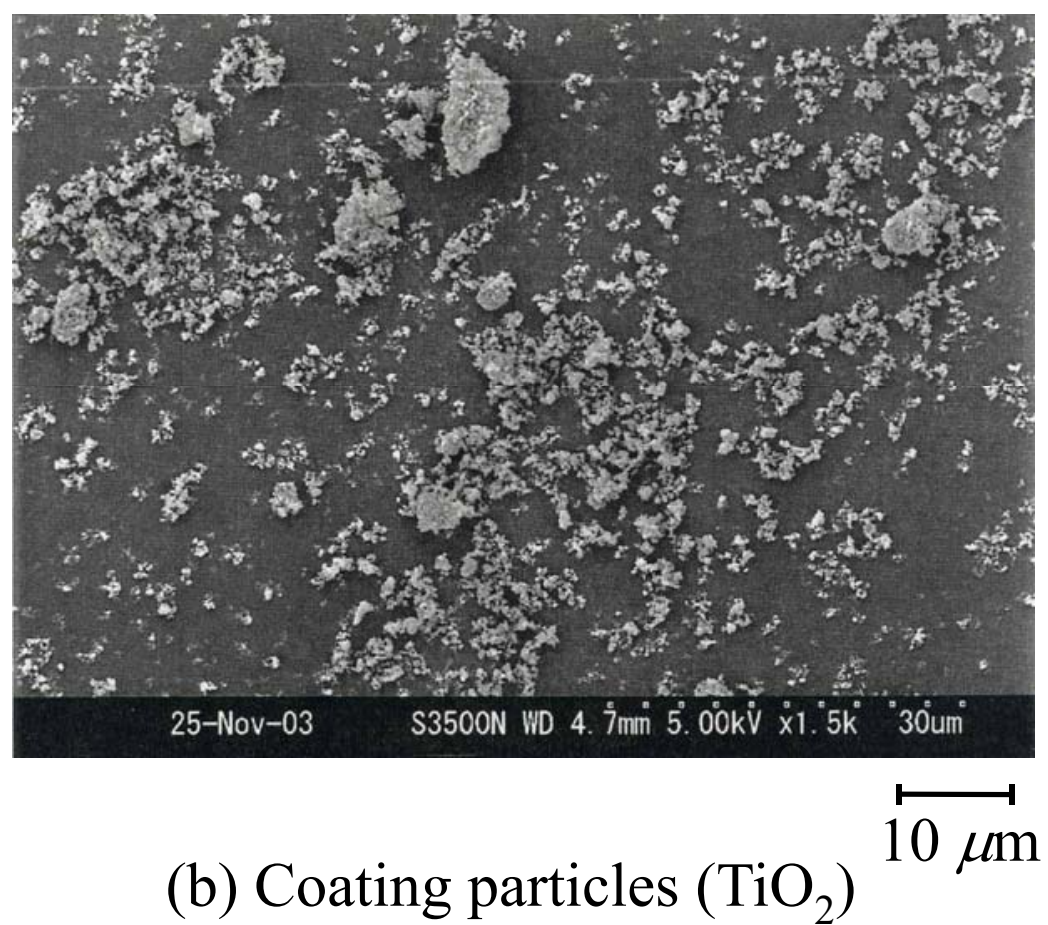

(b) Coating particles $\left(\mathrm{TiO}_{2}\right)$

Fig. 1 SEM photographs of core and coating particles 


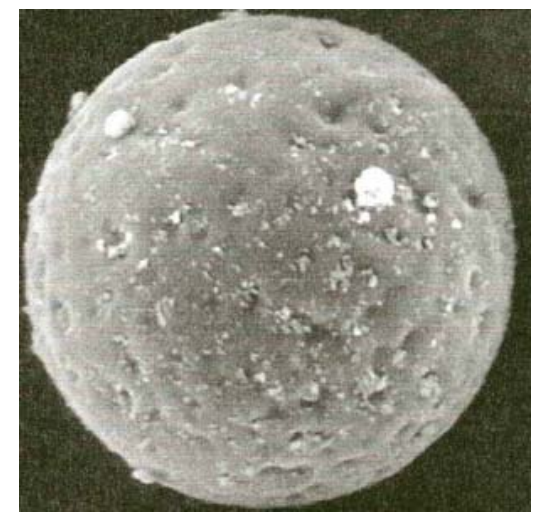

(a) Simple mixing $10 \mathrm{wt} \% \mathrm{TiO}_{2}$ $\left(S_{\mathrm{r}}=0.08\right)$

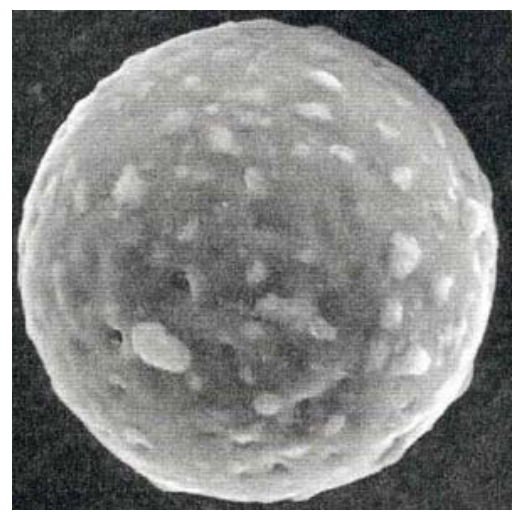

(b) Mechanofusion $1 \mathrm{wt} \% \mathrm{TiO}_{2}$ $\left(S_{\mathrm{r}}=0.13\right)$

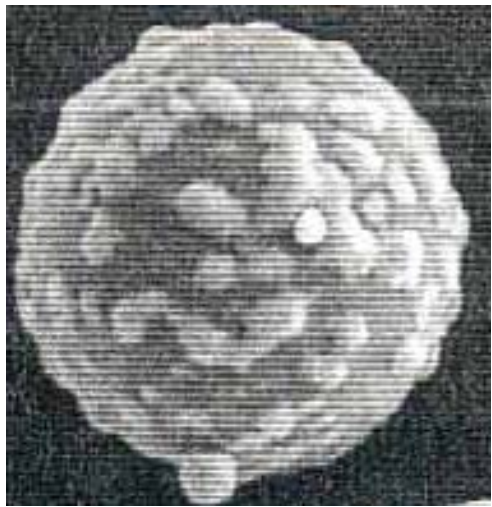

(c) Mechanofusion $10 \mathrm{wt} \% \mathrm{TiO}_{2}$ $\left(S_{\mathrm{r}}=0.48\right)$

Fig. 2 SEM photographs of particles after treatment with nano-particles under different conditions 


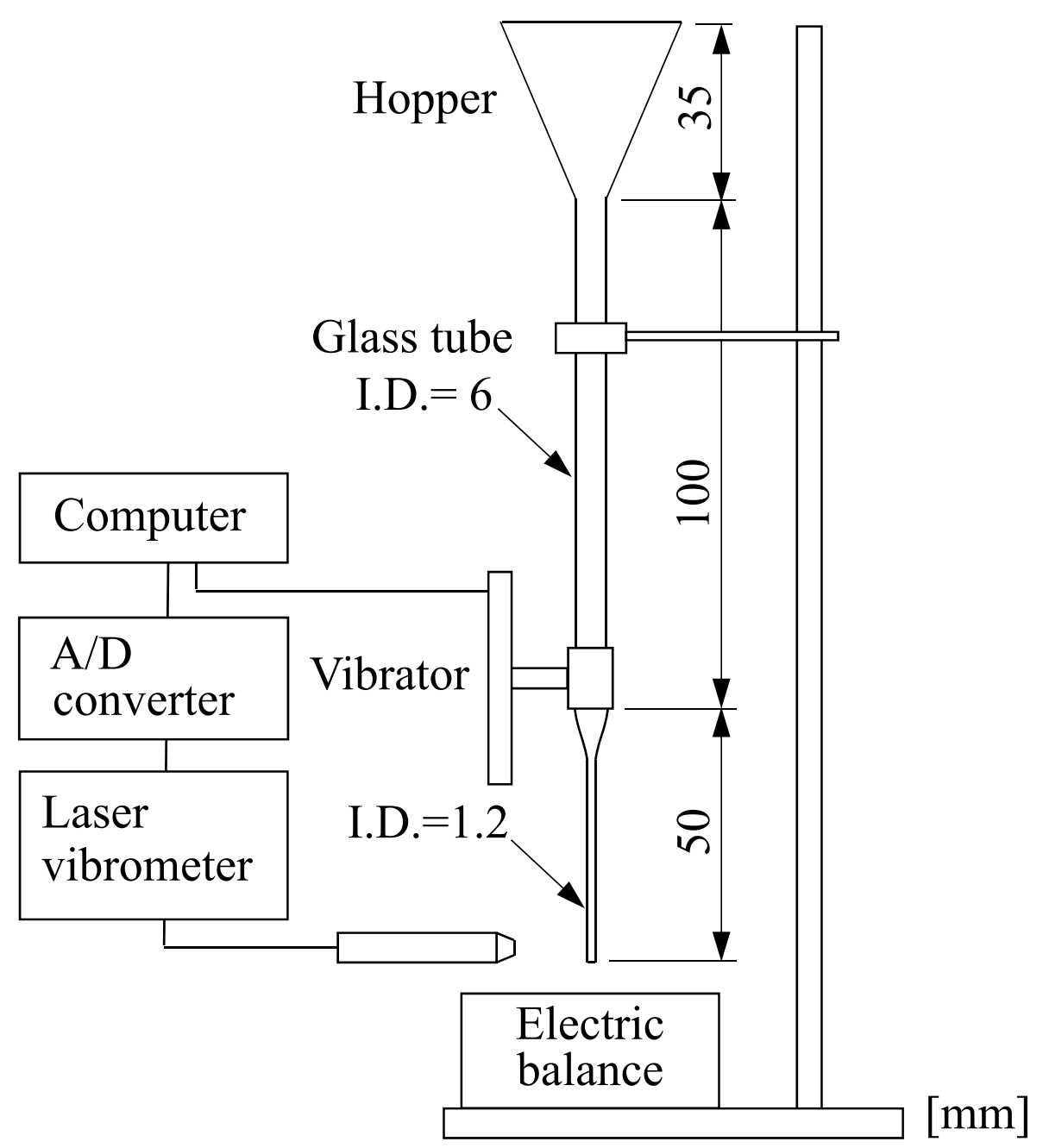

Fig. 3 Experimental apparatus for measuring flowability of powders 


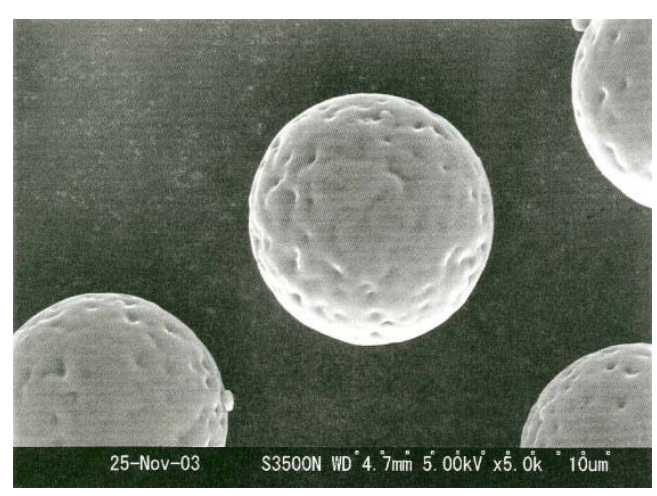

PMMA $\left(0 \mathrm{wt} \% \mathrm{TiO}_{2}\right)$

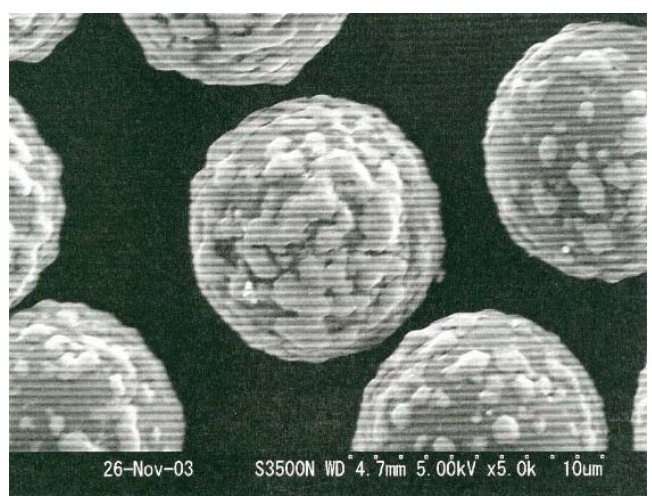

$5 \mathrm{wt} \% \mathrm{TiO}_{2}$

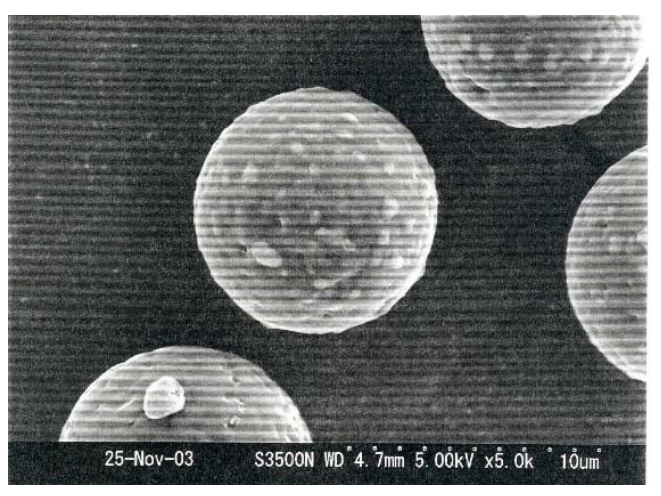

$1 \mathrm{wt} \% \mathrm{TiO}_{2}$

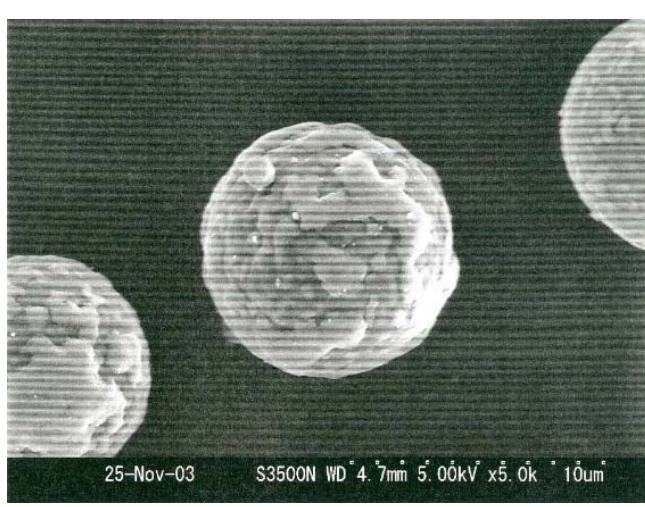

$5 \mathrm{wt} \% \mathrm{Al}_{2} \mathrm{O}_{3}$

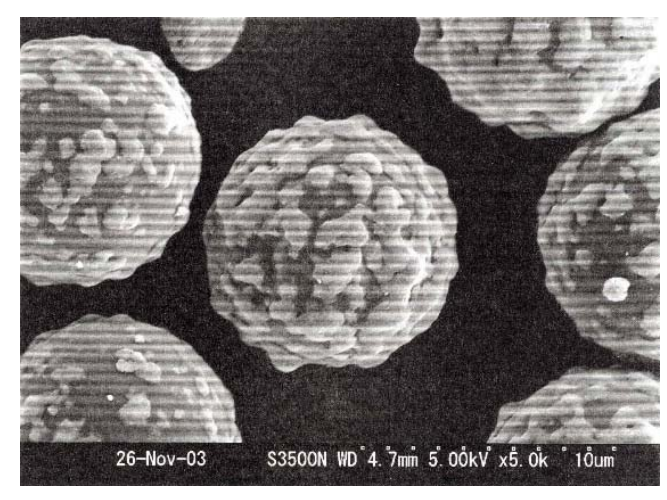

$10 \mathrm{wt} \% \mathrm{TiO}_{2}$

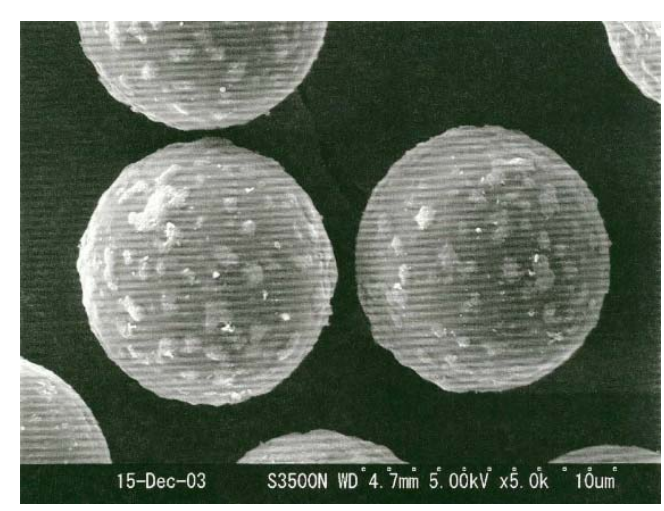

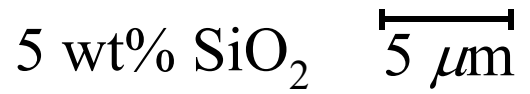

Fig. 4 SEM photographs of particles treated by a mechanofusion method 


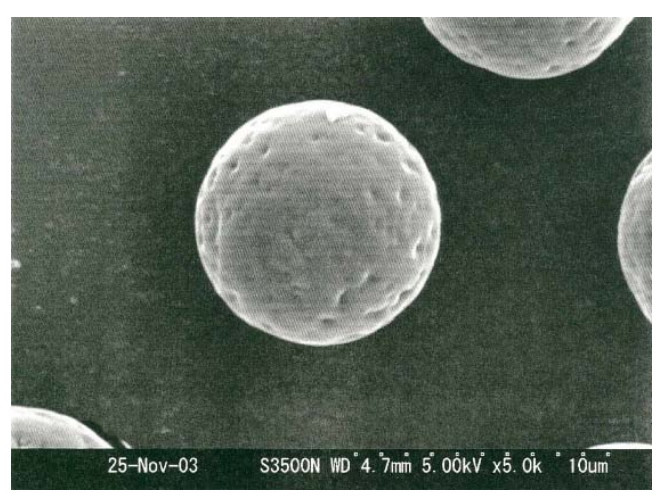

$\operatorname{PMMA}\left(0 \mathrm{wt} \% \mathrm{TiO}_{2}\right)$

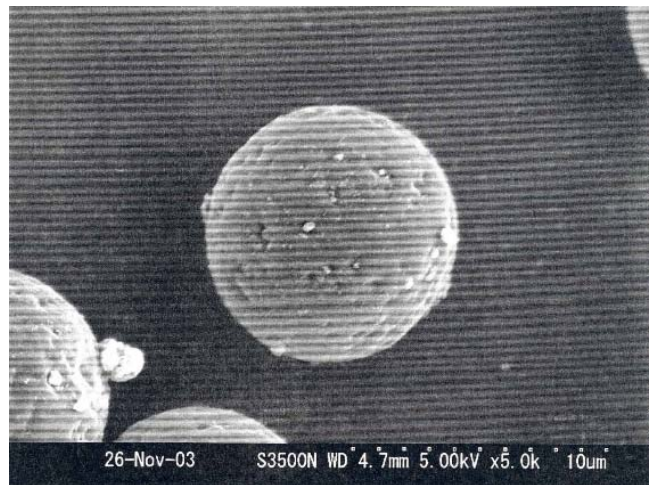

$5 \mathrm{wt} \% \mathrm{TiO}_{2}$

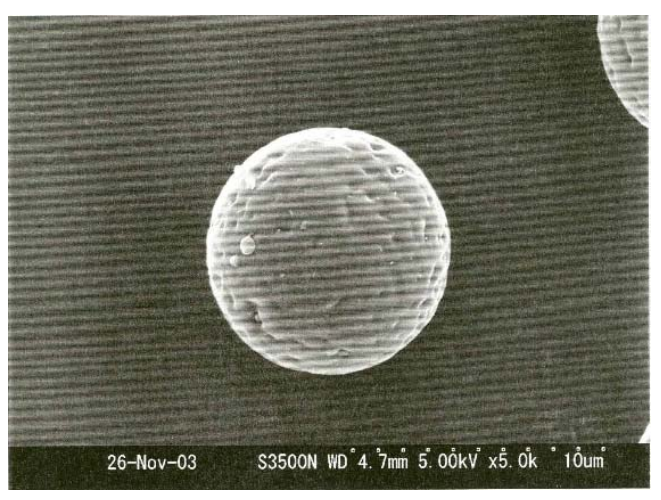

$1 \mathrm{wt} \% \mathrm{TiO}_{2}$

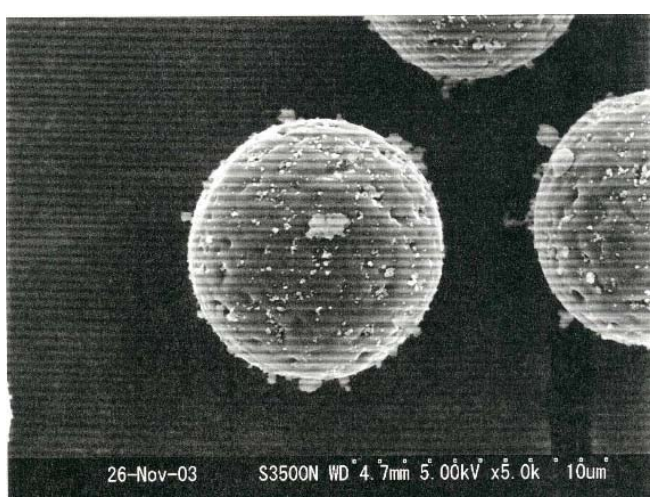

$5 \mathrm{wt} \% \mathrm{Al}_{2} \mathrm{O}_{3}$

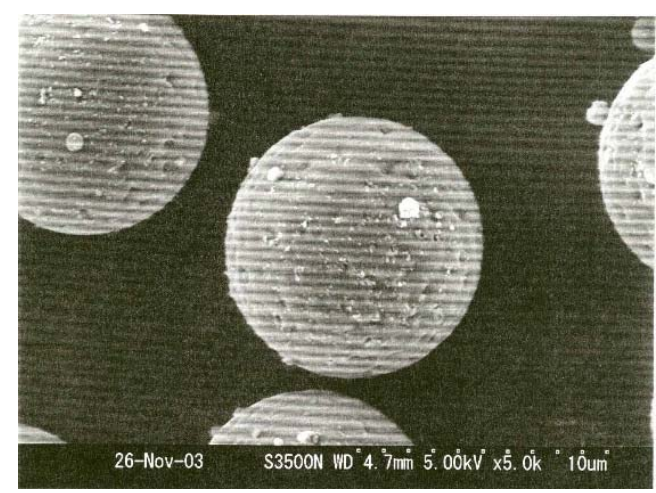

$10 \mathrm{wt} \% \mathrm{TiO}_{2}$

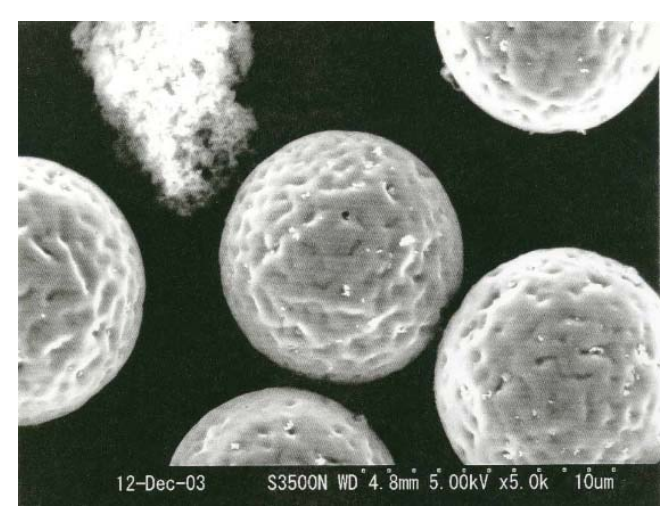

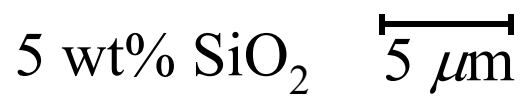

Fig. 5 SEM photographs of particles treated by a simple mixing method 


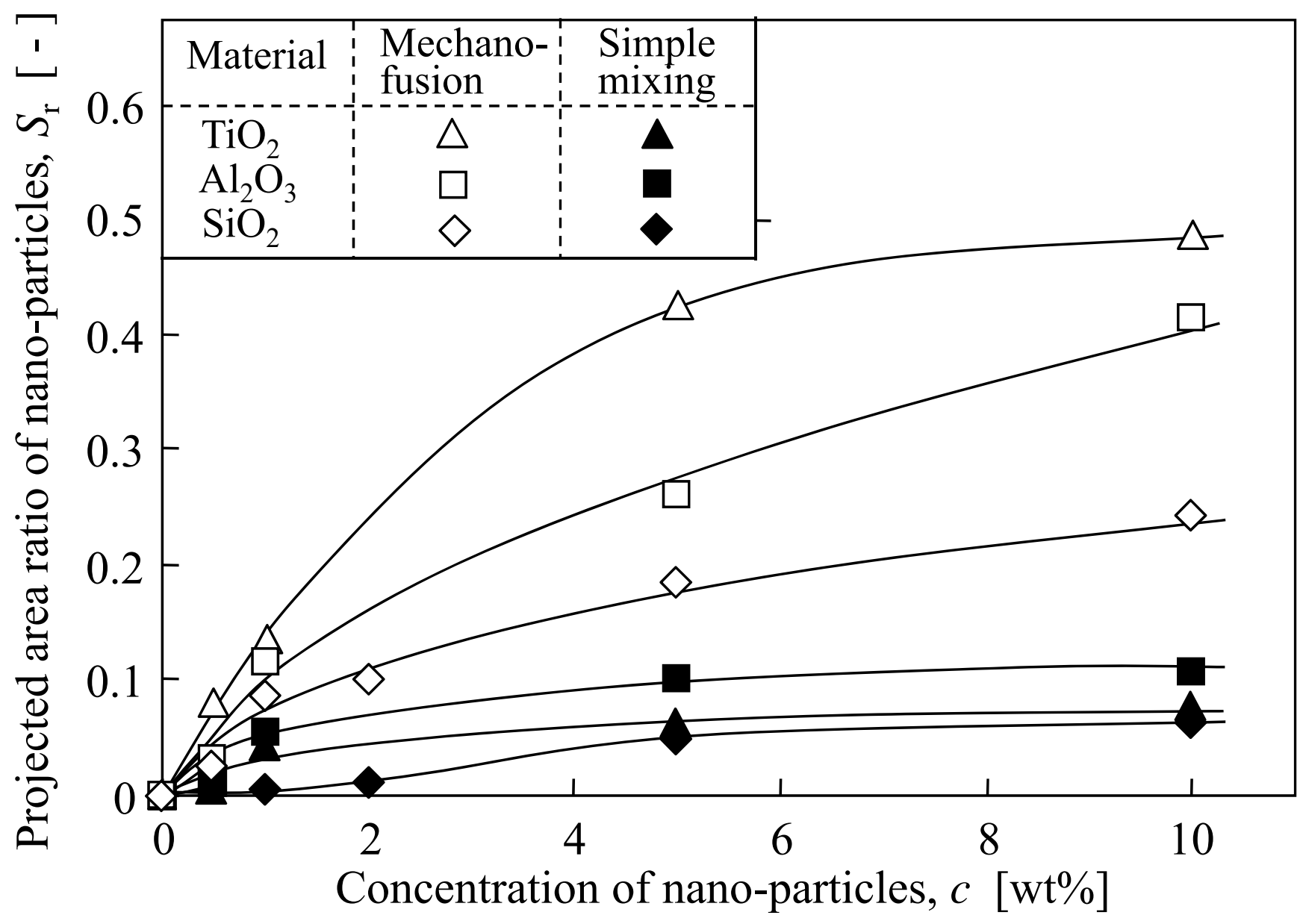

Fig. 6 Characterization of particle surface morphology 


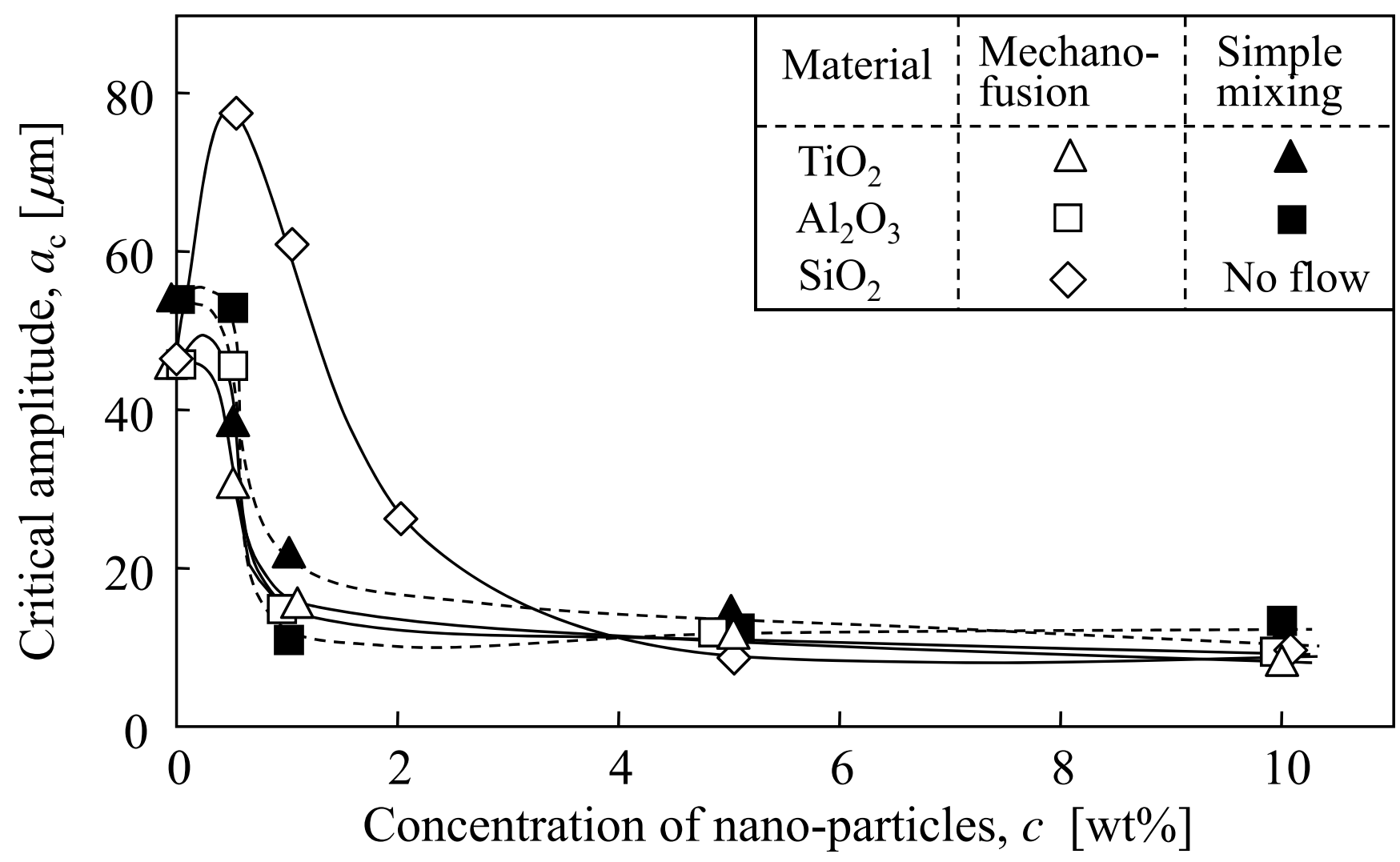

Fig. 7 Relationship between the critical amplitude of vibration and the concentration of nano-particles $(f=400 \mathrm{~Hz})$ 


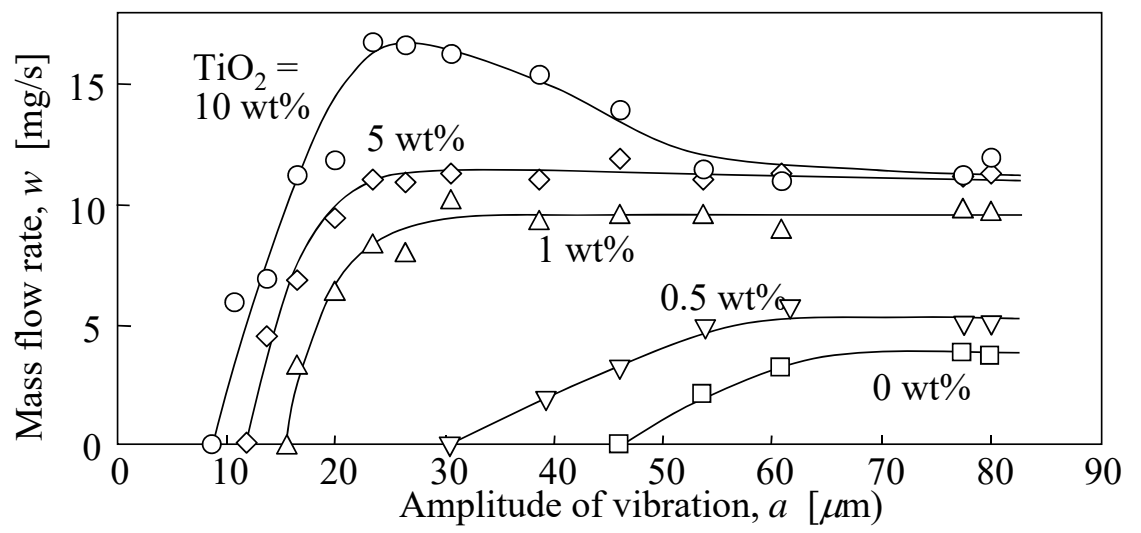

a. $\mathrm{PMMA}-\mathrm{TiO}_{2}$

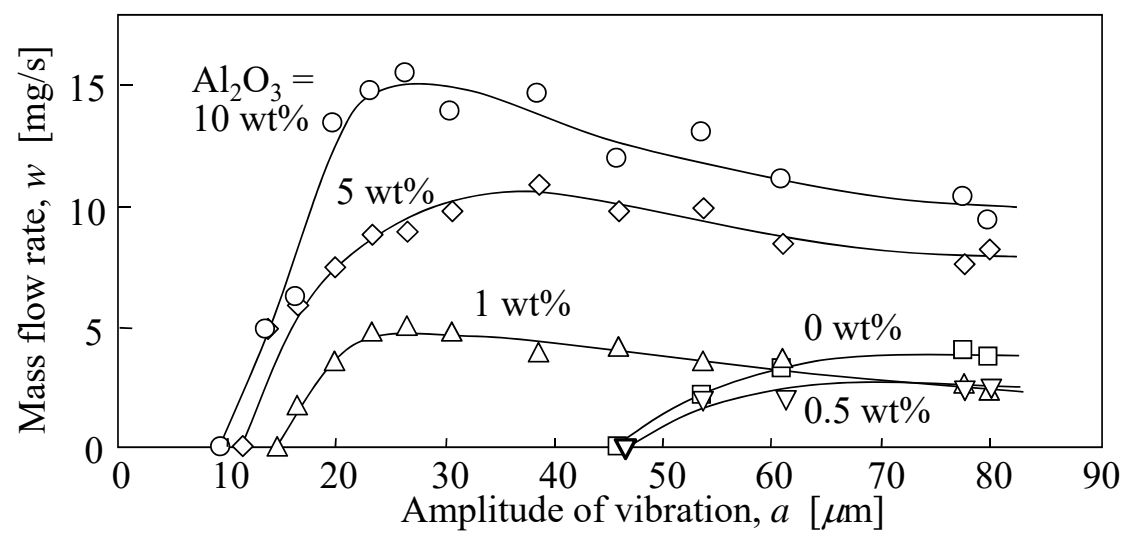

b. $\mathrm{PMMA}-\mathrm{Al}_{2} \mathrm{O}_{3}$

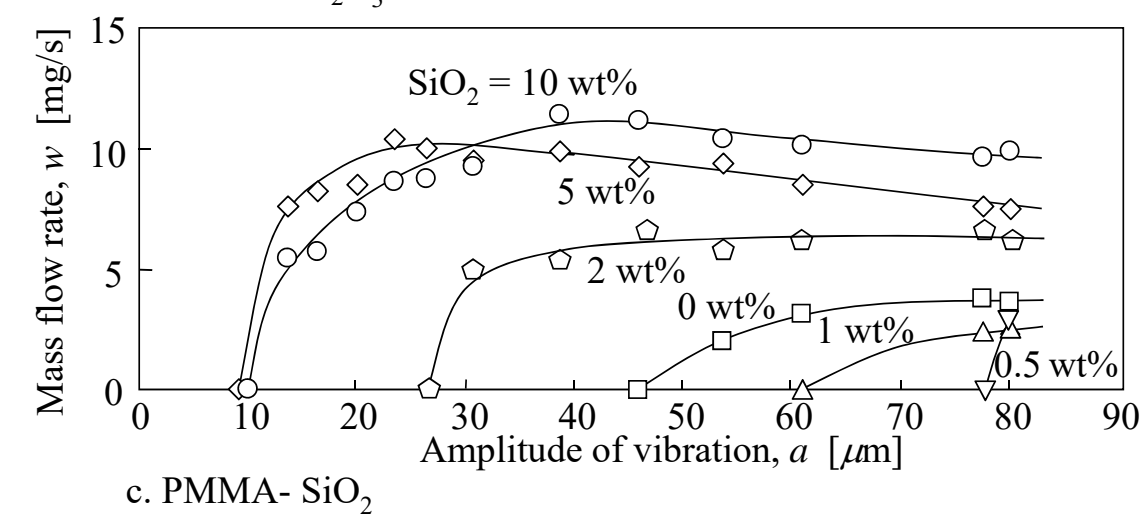

Fig. 8 Mass flow rates of particles after mechanofusion treatment $(f=400 \mathrm{~Hz})$ 


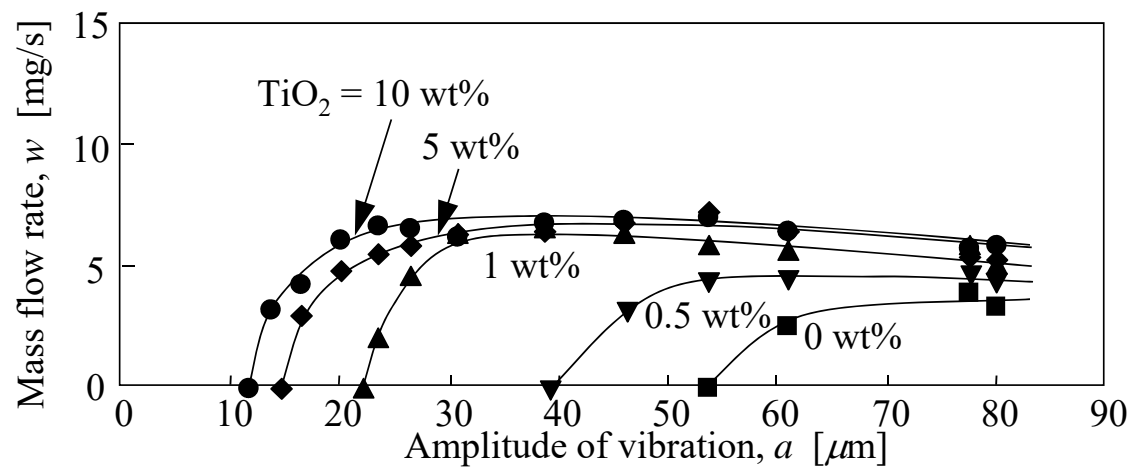

a. $\mathrm{PMMA}-\mathrm{TiO}_{2}$

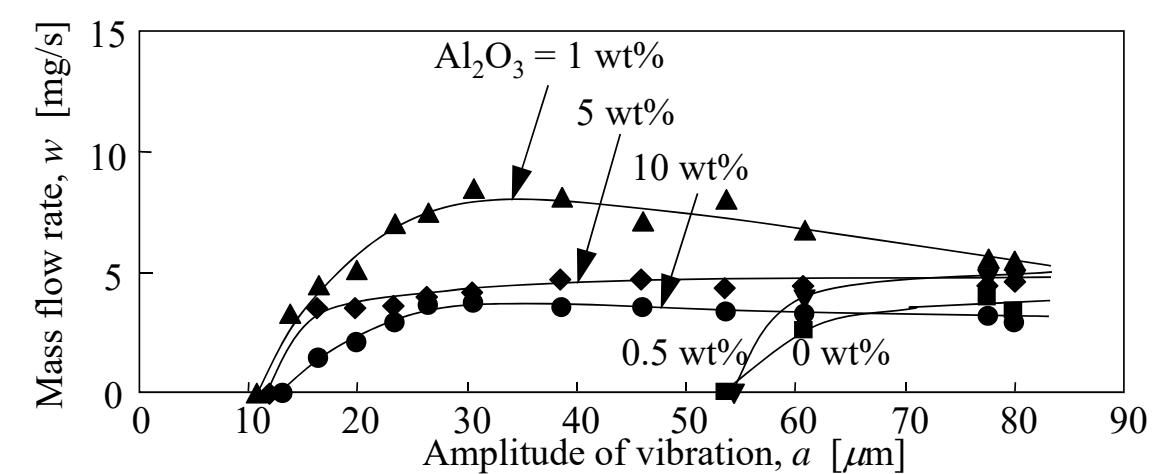

b. $\mathrm{PMMA}-\mathrm{Al}_{2} \mathrm{O}_{3}$

Fig. 9 Mass flow rates of particles after simple mixing $(f=400 \mathrm{~Hz})$ 


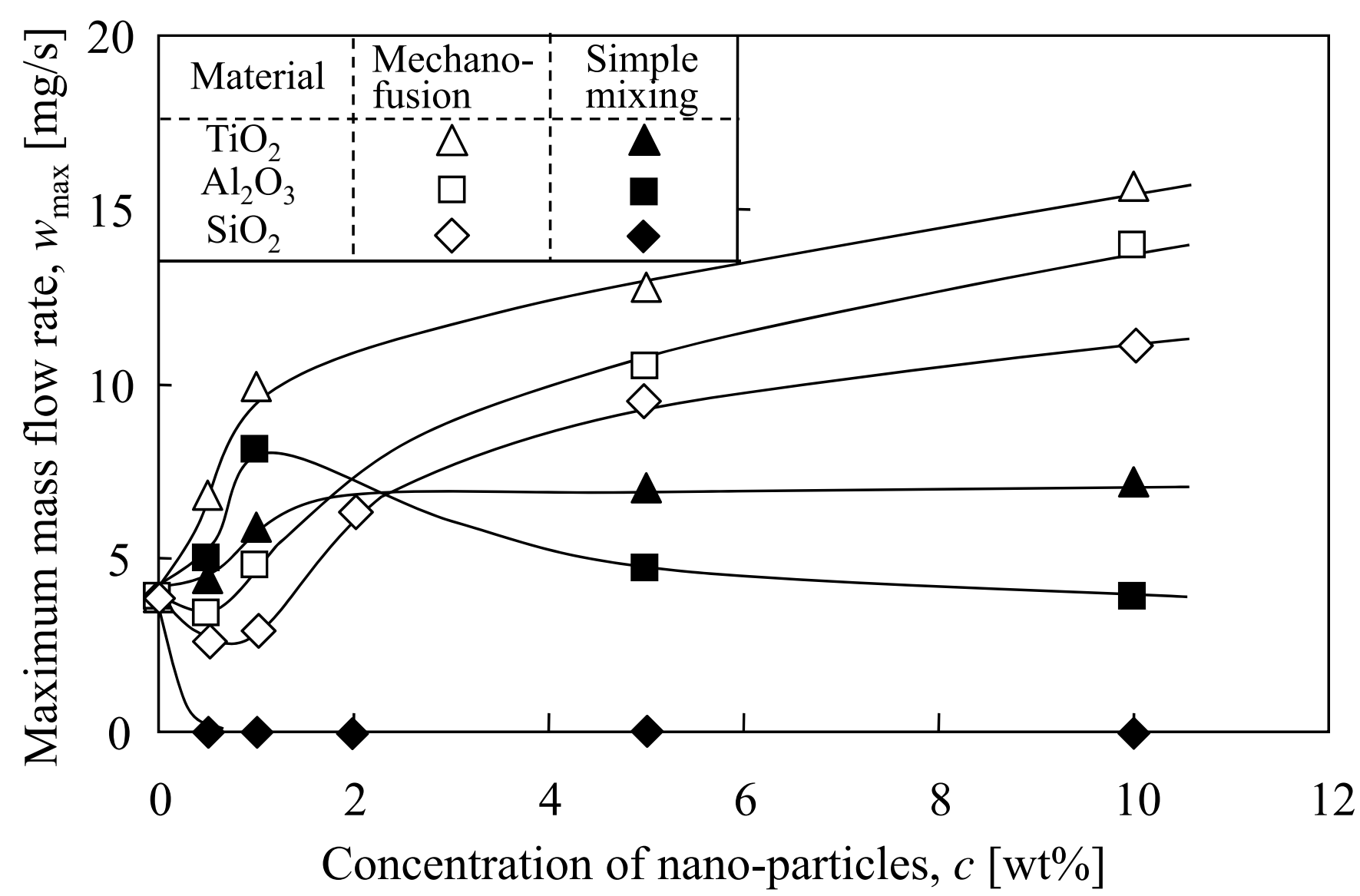

Fig. 10 Relationship between the maximum mass flow rate and the concentration of nano-particles $(f=400 \mathrm{~Hz})$ 


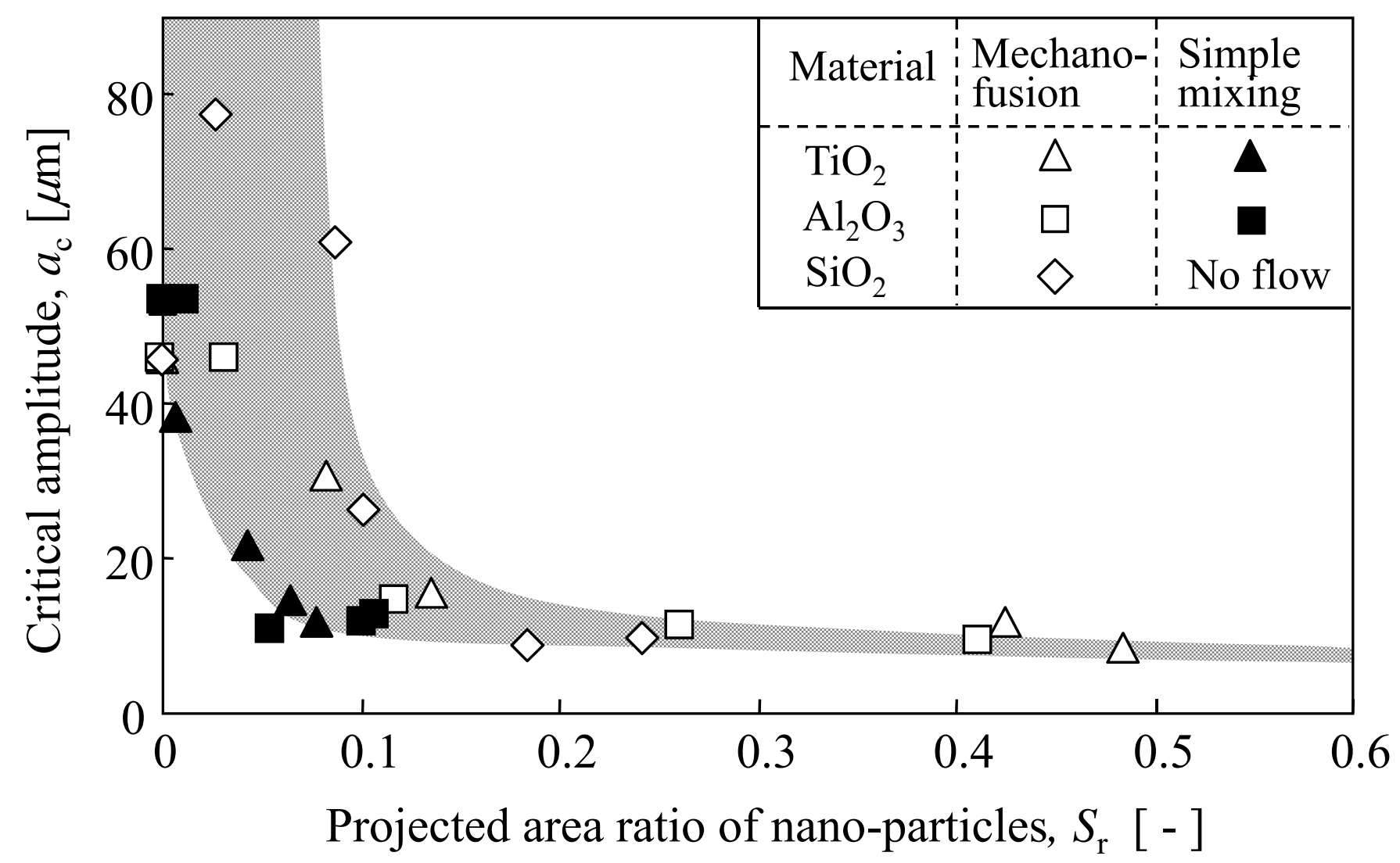

Fig. 11 Relationship between the critical amplitude of vibration and the projected area ratio of nano-particles $(f=400 \mathrm{~Hz})$ 


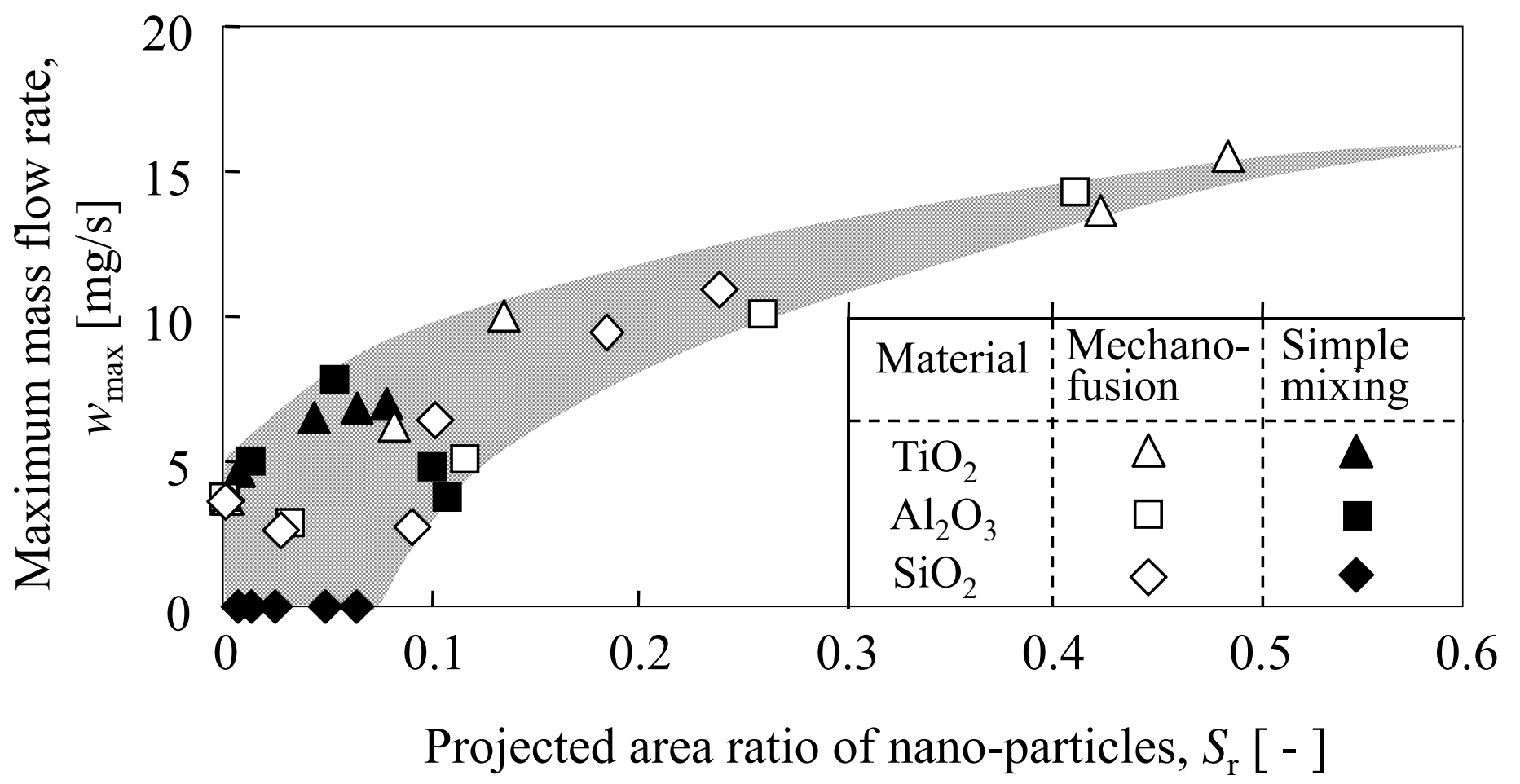

Fig. 12 Relationship between the maximum mass flow rate and the projected area ratio of nano-particles $(f=400 \mathrm{~Hz})$ 